$\stackrel{N / 2}{N}$

Global Journals Inc

s.

\title{
Impact of Conflict Management Styles on Team Performance on Supervisors of Teams in Universities
}

By Dr. Rashid M. Alhamali

King Saud University

Abstract- This study investigates the impact of conflict management (CM) styles on team performance. Conflict Management was conceptualized in terms of five styles: avoiding, integrating, dominating, obliging and compromising. Team performance, on the other hand, was operationalized in terms of team cohesion, team communication, innovativeness, and quality. Five hypotheses regarding the impact of each dimension of CM on team performance were postulated. Gathering data via a questionnaire developed for this study from a sample consisted of 231 employees working at 40 teams in Twenty universities selected from 4 regions. Participants in the work sites were visited by the researcher's assistant to collect data and ensure a high response rate. Two hundred and fifty questionnaires were administered by hand, and 231 were returned completely. Using SPSS and AMOS, research data were entered, coded, analyzed and plotted. The results showed that three conflict management styles (integrating, obliging and compromising) had significant positive effects on team performance while two styles (avoiding and dominating) had significant negative effects on team performance.

Keywords: conflict management styles, team performance, university leadership, quality improvement.

GJMBR-A Classification: JEL Code: D74

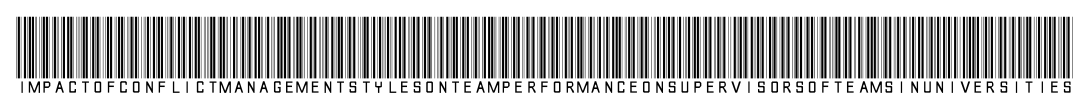

Strictly as per the compliance and regulations of:

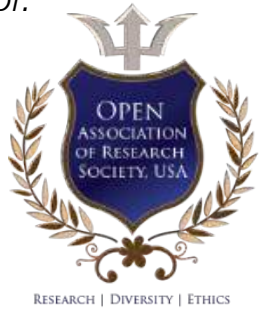

(C) 2019. Dr. Rashid M. Alhamali. This is a research/review paper, distributed under the terms of the Creative Commons Attribution-Noncommercial 3.0 Unported License http://creativecommons.org/licenses/by-nc/3.0/), permitting all non-commercial use, distribution, and reproduction in any medium, provided the original work is properly cited. 


\title{
Impact of Conflict Management Styles on Team Performance on Supervisors of Teams in Universities
}

\author{
Dr. Rashid M. Alhamali
}

Abstract- This study investigates the impact of conflict management (CM) styles on team performance. Conflict Management was conceptualized in terms of five styles: avoiding, integrating, dominating, obliging and compromising. Team performance, on the other hand, was operationalized in terms of team cohesion, team communication, innovativeness, and quality. Five hypotheses regarding the impact of each dimension of $\mathrm{CM}$ on team performance were postulated. Gathering data via a questionnaire developed for this study from a sample consisted of 231 employees working at 40 teams in Twenty universities selected from 4 regions. Participants in the work sites were visited by the researcher's assistant to collect data and ensure a high response rate. Two hundred and fifty questionnaires were administered by hand, and 231 were returned completely. Using SPSS and AMOS, research data were entered, coded, analyzed and plotted. The results showed that three conflict management styles (integrating, obliging and compromising) had significant positive effects on team performance while two styles (avoiding and dominating) had significant negative effects on team performance. In light of these results, the study recommended that the conflict should not be ignored or resolved in a way that suits one of the parties to the conflict and at the expense of the other party. The interests of both parties must be taken into account.

Keywords: conflict management styles, team performance, university leadership, quality improvement.

\section{InTRODUCTION}

$\mathrm{O}$ rganizations seek to improve their outcomes by eliminating some the negative phenomena that occur in the organization such as the conflict between team members (Somech et al., 2009). Teams were regarded and should be as a major block for organizations (Stewart and Barrick, 2000). The reason for the team's importance is to integrate resources and skills of team members (Guimera et al., 2005). Therefore, team performance must be the best. Conflict situations are one of the cases where the performance of a team must be evaluated. Hence, the aim of this study is to explore the effect of conflict management styles on team performance. Aritzeta et al. (2005) stressed that the conflict is very frequent in organizations that rely on teams. For this reason, how the conflict is conducted has an impact on the team's performance.

Author: College of Business Administration, King Saud University, Riyadh, Kingdom of Saudi Arabia. e-mail: rkahtani@ksu.edu.sa
Conflict management (CM) has received considerable attention from Researchers over the years. Examples of CM-related subjects involve studies on conflict management and group decision making (Kuhn et al., 2000), conflict management effect on group effectiveness (DeChurch and Marks, 2001), CM styles and leadership effectiveness (Barbuto Jr and Xu, 2006), differences in conflict management styles from different countries (Kim et al., 2007), exploring conflict management (Stanley and Algert, 2007), CM styles and employee attitudinal outcomes (Chan et al., 2008), conflict management and forgiveness (Rizkalla et al., 2008), team satisfaction and performance (Liu et al., 2008), conflict management between and within teams (Hempel et al., 2009), CM styles and team performance (Somech et al., 2009), the relationship between emotional intelligence and CM styles and job performance (Shih and Susanto, 2010), the influence of collectivism and CM styles (Ma et al., 2010), leadership styles and CM styles (Saeed et al., 2014), CM styles and workplace bullying (Baillien al., 2014), organizational power and CM styles (Riasi and Asadzadeh, 2015) as well as cultural orientation and CM styles (Caputo et al., 2018). Generally, the majority of studies that conducted on CM used five common styles which were avoiding, compromising, dominating, integrating, and obliging (Rahim, 2000; Rizkalla Et al., 2008; Riasi and Asadzadeh, 2015; Zaman and Saif, 2016).

On the other hand, team performance has been investigated as a dependent variable in relationships with numerous variables such as conflict management (Alper et al., 2000), organizational structure and information processing (Carley and Prietula, 2014), team empowerment (Kirkman et al., 2004), transformational leadership (Dionne et al., 2004), authentic leadership (Lyubovnikova et al., 2017), collective leadership (McAuliffe et al., 2017), team mental models (Gardner et al., 2017), team tenure diversity (Yi et al., 2018).

It is noted from previous research that studies on the relationship between conflict management styles and performance of teams are few. Therefore, the importance of the current study stems from the fact that it fills a gap in the theoretical literature, and it is hoped that organizations will benefit from its results, which show the role of good management of the conflict in the performance of the team work. 


\section{il. Literature ReVieW}

\section{a) Conflict management styles}

CM style was defined as a common pattern or behavior that presented in a response to interaction with others in the context of conflict (Kuhn et al., 2000). It is a combination of personality trait, cultural background, and situations (Ting-Toomey eta I., 2001). Researches in general identified five styles of conflict handling, which were avoiding, dominating, integrating, obliging and compromising. Table 1 shows these dimensions and other dimensions.

Table 1: Styles of conflict management

\section{Styles of conflict management}

Avoiding, compromising, dominating, integrating, and obliging.

Avoidance, distributive, integrative, and mixed.

Avoiding, compromising, dominating, integrating, and obliging.

Avoiding, competing, collaborating, compromising, and accommodating.

Avoiding, integrating, compromising, dominating, and obliging.

Avoiding, integrating, compromising, dominating, and obliging.

Avoiding, competing, compromising, collaborating, and accommodating.

Collaboration and competition conflict management styles.

Avoiding, integrating, obliging, compromising and dominating.

Avoiding, fighting, yielding, compromising, and problem solving.

Cooperative conflict management and competitive conflict management.

Cooperative conflict management and competitive conflict management.

Avoiding, problem-solving, yielding and forcing.

Avoiding, integrating, obliging, compromising

Avoiding, accommodating, collaborating, competing and compromising.

Avoiding, compromising, dominating, integrating, and obliging.

Avoiding, compromising, dominating, integrating, and obliging.

Avoiding, problem-solving, accommodating and asserting. Avoiding, forcing and problem-solving

\section{References}

Rahim (2000)

Kuhn et al. (2000)

Rahim (2002)

Slabbert (2004)

Barbuto Jr and Xu (2006)

Yu et al. (2006)

Stanley and Algert (2007)

Liu et al. (2008)

Chan et al. (2008)

Rizkalla et al. (2008)

Hempel et al. (2009)

Somech et al. (2009)

Baillien al. (2014)

Saeed et al. (2014)

Riasi and Asadzadeh (2015)

Abbas and Karage (2015)

Zaman and Saif (2016)

Zhang et al. (2017)

Caputo et al. (2018) b) Dimensions of conflict management in the current study

Based on the review of conflict management styles, the following styles were selected for the current paper; avoidance, distributive, integrative, dominative conflict management styles. A closer look at conflict management patterns in Table 2 indicates that the pattern is the most effective type because it is based on finding the right solution that satisfies both parties (Rahim, 2002). Followed by a style of obliging that puts the interests of others first (Barbuto Jr and $\mathrm{Xu}, 2006$ ), even at the expense of personal interest. We can call it generosity and kindness style. In the third place comes the style of not harming the other party to the conflict through compromise (Chan et al., 2008). It can be called a settlement style. On the other hand, dominating and avoiding are ineffective styles (Chan et al., 2008; Liu et al., 2008), where the former favors personal interests over others while The second avoids conflict without finding a solution to the conflict. This pattern represents a form of withdrawal or disregard of conflict, which means failure to deal with conflict. Differences between these styles can be observed through the definitions showed in Table 2.

Table 2: Conceptualization of CM styles selected for this paper

\begin{tabular}{|c|c|c|}
\hline CM Styles & Conceptualization & \begin{tabular}{|c|} 
References \\
\end{tabular} \\
\hline $\begin{array}{l}\text { - Avoidance } \\
\text { style }\end{array}$ & $\begin{array}{l}\text { A behavior of ignoring organizational conflict in which lose-lose } \\
\text { outcome Emerged. It is a style with low concern For self and } \\
\text { others. Therefore, it represents a failure to approach or } \\
\text { withdrawal from conflict issues. }\end{array}$ & $\begin{array}{l}\text { Kuhn et al. (2000), Rahim } \\
\text { (2002), Barbuto Jr and Xu } \\
\text { (2006), Liu et al. (2008) and } \\
\text { Chan et al. (2008), }\end{array}$ \\
\hline - Integrative style & $\begin{array}{l}\text { A cooperative behavior to find a persuasive solution to both } \\
\text { sides of the conflict in a win-win approach in which parties are } \\
\text { collaborated through information and finding an acceptable the } \\
\text { solution for the conflict issue. It is a style With high concern for } \\
\text { self and others. It is called a problem solving style of conflict } \\
\text { management. }\end{array}$ & $\begin{array}{l}\text { Kuhn et al. (2000), Rahim } \\
\text { (2002), Yu et al. (2006), } \\
\text { Barbuto Jr and Xu (2006), } \\
\text { Chan et al. (2008) and } \\
\text { Zaman and Saif (2016) }\end{array}$ \\
\hline $\begin{array}{l}\text { - Dominative } \\
\text { style }\end{array}$ & $\begin{array}{l}\text { A behavior of using influences to get ldeas accepted in a win- } \\
\text { lose scheme. It is a style with (high concern for self and Low } \\
\text { concern for others. This style is called forcing conflict } \\
\text { management style. }\end{array}$ & $\begin{array}{l}\text { Rahim (2002), Barbuto Jr } \\
\text { and Xu (2006), Chan et al. } \\
\text { (2008), Baillien al. (2014) }\end{array}$ \\
\hline
\end{tabular}


- Obliging style $\mathrm{A}$ behavior of meeting others needs Based on the lose-win outcome. It is a style with high concern for others and low Concern for self. It also named yielding conflict management style

- Compromising style
A conflict-handling behavior that based on finding an accepted solution based No win-no lose scheme. It is a style with high intermediate concern for self and others.
Rahim (2002), Barbuto Jr and $\mathrm{Xu}$ (2006), Chan et al. (2008), Baillien al. (2014)

Rahim (2002), Liu et al. (2008), Chan et al. (2008); Zaman and Saif (2016)

\section{c) Team performance}

Teams have been defined in terms of two major elements: the number of members and goals, that is, a team consists of two or more members Seeking to achieve a common goal. Consequently, team performance was Defined as a team's ability to meet its goals (Bell, 2007). According to Dionne et al. (2004), team performance has been evaluated in the literature as a system of inputs, processes, and outputs, where the team processes Resources to reach the desired results. The authors conceptualized team performance in terms of three dimensions; team cohesion, team Communication and conflict management. Melita et al. (2003) added another Dimension of team performance which was team innovation. Researchers have identified many features that make the team effective such as team cohesiveness, effective team communication, team innovations, conflict management and the team overall performance (Melita et al., 2003; Dionne et al., 2004; Zhou et al., 2015). In a study on the teams of research and development projects, Keller (2006) used three dimensions to evaluate performance, schedule performance, technical quality, and cost performance. Less cohesive Teams have poor performance (Thompson et al., 2015). Adopting Pearce and Sims (2002) scale of team effectiveness, Zhou et al. (2015) evaluated team performance based on six dimensions comprised of output, quality, change, organizing and planning, interpersonal, and overall Effectiveness. Howard et al. (2002) used quantity and quality of output as well as the resource and administrative efficiency as four dimensions of team Performance dimensions. Table 3 displayed the most common dimensions of team performance.

Table 3: Dimensions of team performance

\begin{tabular}{ll}
\hline \multicolumn{1}{c}{ Team performance dimensions } & \multicolumn{1}{c}{ References } \\
\hline Quantity and quality of output, resource and administrative efficiency. & Howard et al. (2002) \\
Team cohesion, team communication, and team innovations. & Melita et al. (2003) \\
Process improvement and customer satisfaction & Kirkman et al. (2004) \\
Team cohesion, team communication, and conflict management. & Dionne et al. (2004) \\
Schedule performance, technical quality, and cost performance & Keller (2006) \\
Efficiency, work excellence, innovativeness and quality. & Kostopoulos and Bozionelos (2011) \\
Output, quality, change, organizing and planning, Interpersonal, and overall effectiveness. Zhou et al. (2015)
\end{tabular}

d) Hypotheses development

CM styles were used in previous studies as an independent variable about other dependent variables such as group decision making (Kuhn Et al., 2000), group effectiveness (DeChurch and Marks, 2001), employee attitudinal outcomes (Chan et al., 2008). In other studies, CM styles were used as the dependent variable (Yu et al., 2006). Table 4 shows examples of these studies. For this study, CM styles were used as independent variables to study their relationships with team performance. Paul et al. (2004) Found a positive impact of collaborative conflict style on team performance in terms of perceived quality and participation. Findings of DeChurch et al. (2013) Confirmed that collaborating, avoiding, and competing for conflict is positively related to team performance. According to Hempel et al. (2009), cooperative and competitive conflict handling styles have positive effects on trust which in turn affects team performance. Kim et al. (2007) conducted a study to explore conflict management styles using a sample of employees form different countries; e.g., China, Japan, and South Korea and found that the dominant conflict handling among Japanese employees was compromising while the dominant style among Chinese and Korean employees is obliging. Studying the effect of conflict management styles on team effectiveness, Gull et al. (2012) found a moderate influence on team effectiveness. Particularly, the results revealed positive effects of accommodating and collaborative styles on team effectiveness, while the competing style has no significant effect on team effectiveness. In contrast, avoiding and compromising styles have a negative relationship with team effectiveness. 
Table 4: Relationships between CM styles and other variables

\begin{tabular}{|c|c|c|c|c|}
\hline Year & IV & DV & Results & References \\
\hline 2000 & CM styles & $\begin{array}{ll}\text { Group } & \text { decision } \\
\text { making } & \end{array}$ & $\begin{array}{l}\text { Integrative CM style results in positive outcomes of group } \\
\text { decision making. }\end{array}$ & Kuhn et al. \\
\hline 2001 & CM styles & $\begin{array}{l}\text { Group } \\
\text { effectiveness }\end{array}$ & CM style positively related to group effectiveness. & $\begin{array}{l}\text { DeChurch and } \\
\text { Marks }\end{array}$ \\
\hline 2006 & $\begin{array}{l}\text { Emotional } \\
\text { intelligence }\end{array}$ & CM styles & $\begin{array}{l}\text { Emotional intelligence has significant effects on integrating } \\
\text { and compromising }\end{array}$ & Yu et al. \\
\hline 2007 & CM styles & - & $\begin{array}{l}\text { The dominant CM among Chinese and Korean employees are } \\
\text { obliging, while the dominant CM among Japanese employees } \\
\text { are compromising }\end{array}$ & Kim et al. \\
\hline 2008 & CM styles & $\begin{array}{l}\text { Employee } \\
\text { attitudinal } \\
\text { outcomes }\end{array}$ & $\begin{array}{l}\text { Integrating CM style significantly related to employees job } \\
\text { satisfaction and turnover intention. }\end{array}$ & Chan et al. \\
\hline 2008 & CM styles & Team satisfaction & $\begin{array}{l}\text { Collaboration conflict management style has a significant } \\
\text { effect on the team satisfaction }\end{array}$ & Liu et al. \\
\hline 2009 & CM styles & $\begin{array}{l}\text { Team } \\
\text { performance }\end{array}$ & $\begin{array}{l}\text { cooperative conflict style has a significant effect on a team } \\
\text { performance }\end{array}$ & Somech Et al. \\
\hline 2010 & CM styles & Job performance & $\begin{array}{l}\text { Integrating CM style has a significant effect on job } \\
\text { performance }\end{array}$ & $\begin{array}{l}\text { Shih and } \\
\text { Susanto }\end{array}$ \\
\hline 2014 & $\begin{array}{l}\text { Leadership } \\
\text { styles }\end{array}$ & CM styles & $\begin{array}{l}\text { Managers with transformational leadership style adopt } \\
\text { integrating and obliging CM styles, managers with } \\
\text { transactional leadership style adopt compromising CM style. }\end{array}$ & Saeed Et al. \\
\hline 2015 & $\begin{array}{l}\text { Organization } \\
\text { power }\end{array}$ & ICM styles & $\begin{array}{l}\text { Reward power is positively related to accommodating CM } \\
\text { style }\end{array}$ & $\begin{array}{l}\text { Riasi and } \\
\text { Asadzadeh }\end{array}$ \\
\hline 2018 & $\begin{array}{l}\text { Cultural } \\
\text { orientations }\end{array}$ & CM styles & Cultural orientations are positively influenced CM styles & Caputo et al. \\
\hline
\end{tabular}

Inconsistently, the results of Somech et al. (2009) who investigated the impact of conflict management styles on team effectiveness indicated that competing style was negatively associated with team effectiveness. Based on these studies, the following hypotheses were restated:

H1: Integrating conflict style has a positive significant effect on team performance.

H2: Obliging conflict style has a positive significant effect on team performance.

H3: Compromising conflict style has a positive significant effect on team performance.

H4: Avoiding conflict style has a negative significant effect on team performance.

H5: Dominating conflict style has a negative significant effect on team performance.

\section{ili. Methodology}

a) Research sample and data collection

Using a multi-stage technique as introduced by Hair Jr. et al. (2015), a random sample of 4 regions were identified from which a random sample consisted 20 universities were selected, then a random sample comprised of 40 teams were chosen. The average number of members in these teams ranged from 3-10 members, specifically, there were 250 employees. Hence, data were collected from 250 employees using a questionnaire developed for this study. A total of 231 questionnaires were returned complete and valid for statistical analyses with a response rate of $92.4 \%$. Responses of team members were used to conduct analyses, therefore, our data were not aggregated at the team level.

\section{b) Measures}

Conflict management styles were measured based on previous studies using three indicators for each style; avoiding (1-3), integrating (4-6), dominating (7-9), obliging (10-12) and compromising (13-15) (Kim et al., 2007; Hempel et al., 2009; Somech et al., 2009; Gull et al., 2012; DeChurch et al., 2013). Team performance was measured based on employees' ratings. Six dimensions were used to assess team performance, which was members commitment to the team, work quality, interpersonal skills, initiatives, knowledge of tasks and overall performance (Stewart and Barrick, 2000). Therefore, six items were used to measure team performance.

\section{c) Exploratory Factor Analysis (EFA)}

In order to ascertain the appropriateness of the data for exploratory factor analysis, two tests were performed: Kaiser-Meyer-Olkin (KMO) and Bartlett's test for Sphericity. The value of a $\mathrm{KMO}$ test ranges from 0 to 1 , and the closer the test value of a KMO to 1, the more suitable the data for factor analysis. The test value is acceptable if it is greater than 0.05 . The value of the Bartlett's test for Sphericity should be statistically significant. If these conditions are met, a factor analysis is possible. The results showed that the two previous conditions were met. The value of the KMO was greater 
than $0.05(\mathrm{KMO}=0.874)$ and the value of the Bartlett's test was significant $(P=0.021)$. The results of EFA can be seen in Table 5. It was revealed that all items of $\mathrm{CM}$ styles were loaded on 5 factors with loadings greater than 0.71 . A measurement model with factor loadings $\geq$ 0.70 is acceptable (Shook et al., 2004). In terms of reliability, the results indicated that composite reliability (CR) and Cronbach's coefficient alpha values were greater than 0.70 (Ogedegbe et al., 2003). Convergent validity values as measured by AVEs were greater than 0.50 (Hair et al., 2011).

Table 5: Results of exploratory factor analysis

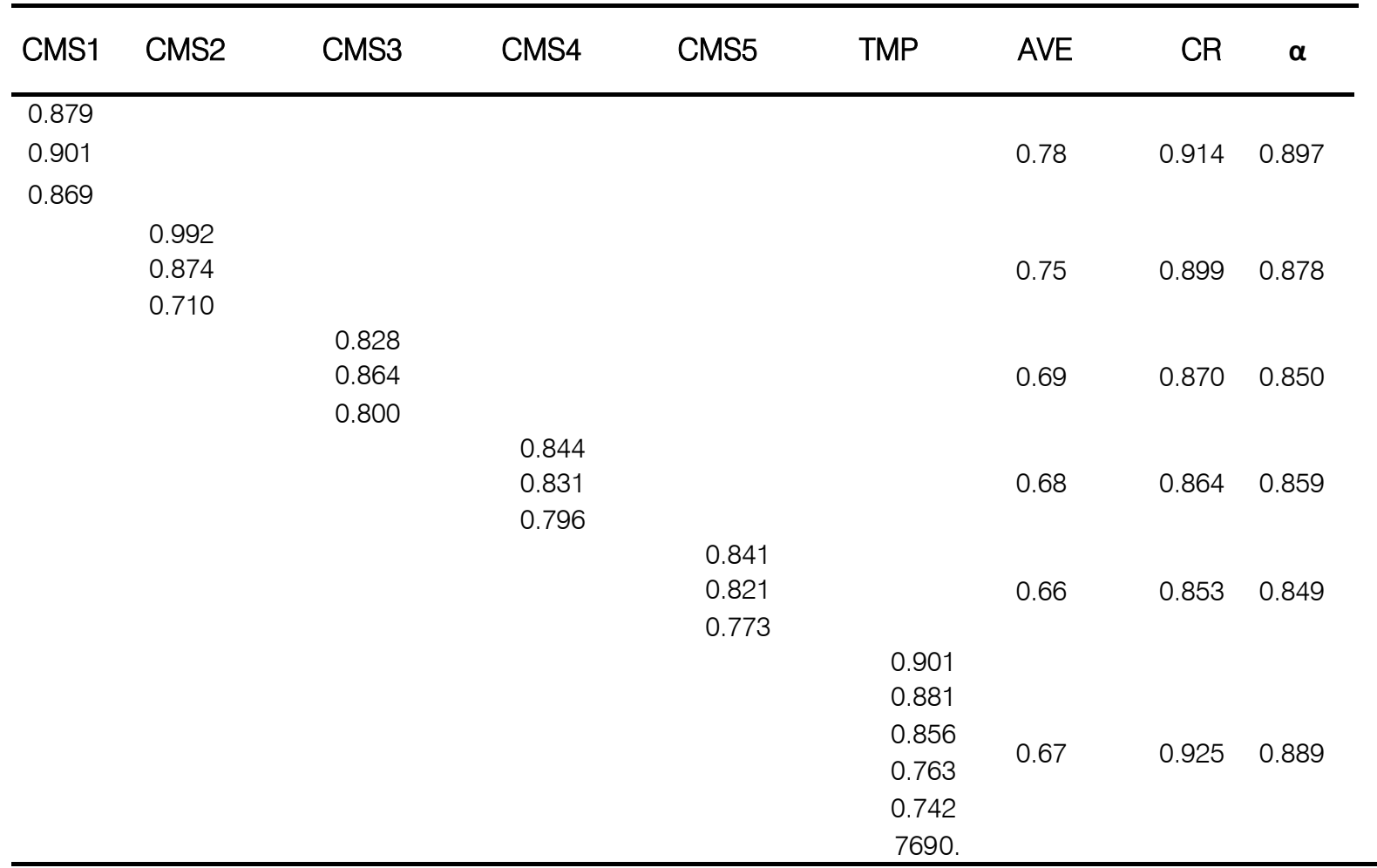

CMS1: avoiding, CMS2: integrating, CMS3: dominating, CMS4: obliging, CMS5: compromising, TMP: team performance.

d) Structural Equation Modeling (SEM)

Hempel et al. (2009) suggested two steps to examine the structural model: First, testing the postulated structural model in terms of goodness-of-fit indices in order to investigate the model ability to explain relationships between variables. If the fit of the model is confirmed, the second step starts, which is hypotheses testing in which the relationship between variables is investigated. Structural model fit was evaluated by chisquare to degree of freedom ratio $\left(x^{2} / d f\right)$, the goodness of fit index (GFI), the comparative fit index (CFI), the root mean square error of approximation (RMSEA) and the non-normed fit index (NNFI) as suggested by Barbuto Jr and $\mathrm{Xu}$ (2006) and Kim et al. (2015). The results of structural model goodness-of-fit indices as shown in Table 6 indicated a satisfactory overall fit of the model.

Table 6: Results of structural model goodness-of-fit indices

\begin{tabular}{lll}
\hline \multicolumn{1}{c}{ Indices } & Value & Result \\
\hline Chi-square to degree of freedom ratio $\left(x^{2} / \mathrm{df}\right)$ & 1.59 & Confirmed \\
The goodness of fit index (GFI) & 0.921 & Confirmed \\
The comparative fit index (CFI) & 0.911 & Confirmed \\
The root mean square error of approximation (RMSEA) & 0.051 & Confirmed \\
The non-normed fit index (NNFI) & 0.961 & Confirmed \\
\hline
\end{tabular}

Figure (1) shows the structural model of the study in which five CM styles and team performance were measured as observed variables. The results showed that conflict management styles exist in the different teams in the universities in a moderate degree in terms of the values of means for integrating ( $\mathrm{M}=$
3.64), obliging $(M=3.61)$, dominating $(M=3.60)$, compromising ( $M=3.58)$ and avoiding $(M=3.55)$. The figure indicates that integrating style has a positive significant effect on team performance. This style is the most influential one on team performance $(B=0.262$, C.R $=7.011, P=0.000$ ), followed by compromising 
style $(B=0.224, C . R=5.73, P=0.001)$ and obliging $(B$ $=0.190, C \cdot R=4.245, P=0.024)$. These results confirm the acceptance of the three hypotheses: $\mathrm{H} 1, \mathrm{H} 2$ and $\mathrm{H} 3$ that assume positive effects of these variables on team performance. On the other hand, the results point out that avoiding style has a negative significant effect on team performance $(B=-0.130, C . R=3.210, P=0.031)$ and a negative significant effect of dominating style on team performance $(B=-0.220, C . R=3.711, P=$ $0.021)$. These results indicate that $\mathrm{H} 4$ and $\mathrm{H} 5$ were supported. The CM style that has the most negative effect on team performance is the dominating style.

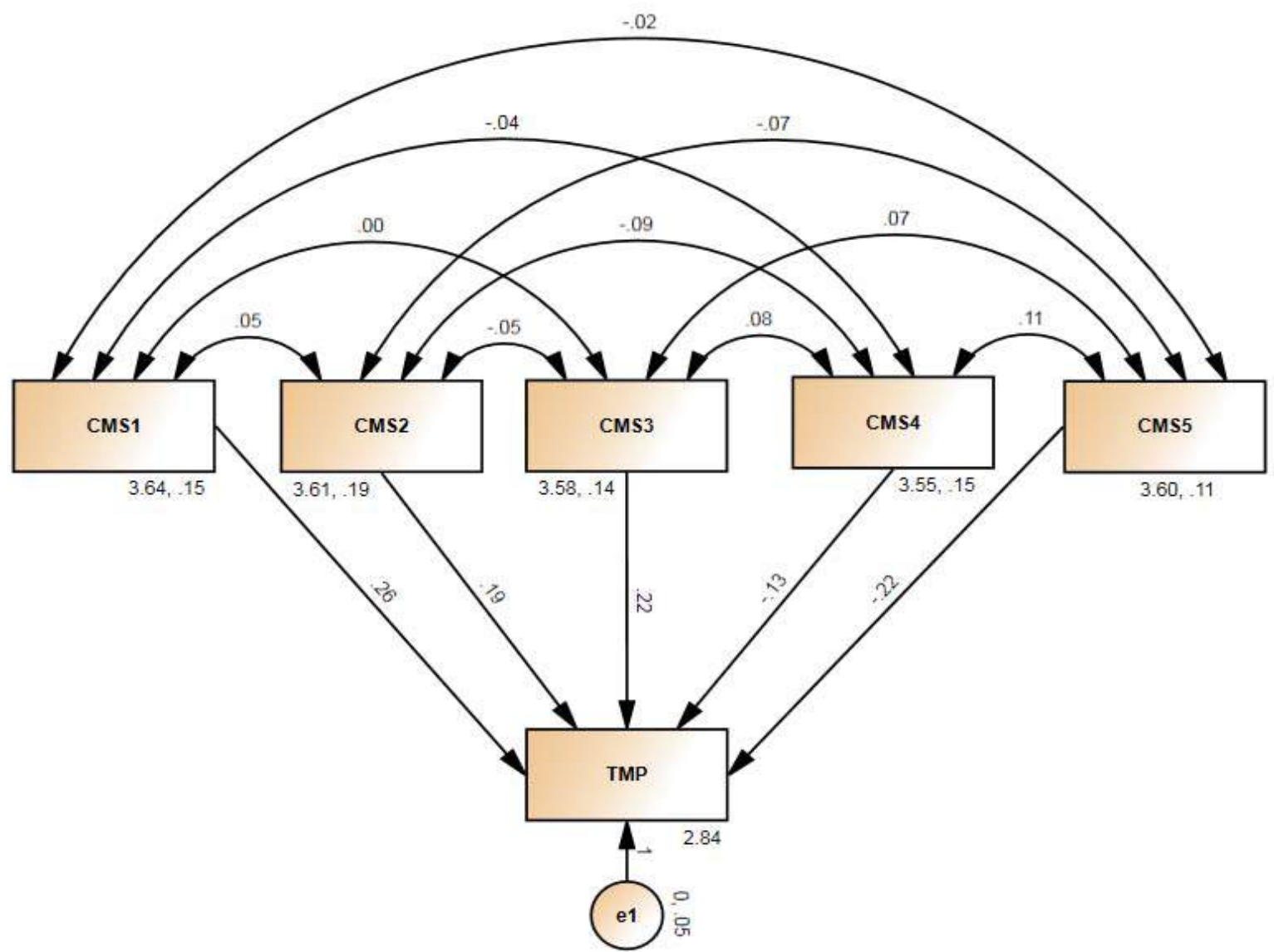

Figure 1: Results of structural model

\section{Discussion and Conclusion}

The aim of this study was to determine the effects of five styles of conflict management on team performance using a sample chosen from members of teams working at twenty universities. The results showed that integrating, compromising and obliging styles had positive significant effects on team performance. While avoiding and dominating styles had negative significant effects on team performance. It is logical that the style of integration is the most style that had a positive impact on team performance. This style represents a cooperative behavior aimed at finding a suitable solution to the conflict so that the parties to the conflict are finally satisfied. This pattern was dubbed by researchers and practitioners as win-win style (Kuhn et al., 2000; Rahim, 2002; Yu et al., 2006; Barbuto Jr and Xu, 2006; Chan et al. (2008) and Zaman and Saif, 2016). The compassing style is conflict handling style that based on finding a settlement that does not cause loss to any party to the conflict (Rahim, 2002, Liu et al., 2008, Chan et al., 2008 and Zaman and Saif, 2016). On the other hand, the style of obliging means favoritism by one party to solve the conflict by taking care of the interests of others This is the most flexible mode of dealing with conflict situations (Rahim, 2002, Barbuto Jr and Xu , 2006, Chan et al., 2008 and Baillien al., 2014).

In contrast, the dominating style conflict management refers to indifference to others and a focus on personal interests, so this style has a significant negative impact on the performance of the team (Rahim, 2002, Barbuto Jr and Xu , 2006, Chan et al., 2008 and Baillien al., 2014). Finally, avoidance means ignoring the conflict and not providing any solutions. In many cases, the reason for ignoring the conflict is the inability to find an appropriate solution to the conflict 
(Kuhn et al., 2000, Rahim, 2002, Barbuto Jr and Xu, 2006, Liu et al., 2008 and Chan et al., 2008). In the light of the foregoing, it was concluded that conflict is a normal situation in organizations, but what is important is how to deal with it in the right way. There are, of course, a number of styles by which conflict can be addressed on the basis of the end result of using a specific style. For example, some styles offer suitable solutions for parties, some of which mean sacrificing one side to the other. The most negative styles are those that provide a solution and force others to comply with it. Moreover, ignoring the conflict also has a negative impact on team performance.

\section{Recommendations, Limitations and Future ResEARCH}

The study recommends that conflict parties and conflict resolution in organizations not to ignore conflict or provide a solution and force others to accept it because these two methods of dealing with conflict are the worst. Alternatively, the co-operative style, i.e., integrating style can be used as much as possible. If this is not possible, other methods can be used to satisfy conflict parties. The current study was conducted using data collected from team members to assess their performance. It is preferable to measure the performance of a team relying on a party other than the team members (D'Innocenzo et al., 2016). Tröster et al. (2014) rated the performance of self-managed teams via experts. Future research are recommended to evaluate team performance based on supervisors' ratings. In a study by Hempel et al. (2009), five control variables were suggested; team-size, organization-size and age, organization age and industry. In the current study, no control variables were used. Therefore, it is advisable to conduct a future study that takes into account of control variables such as organization size and age. Furthermore, demographic characteristics of participants played a significant role in adopting conflict handling style, Zhang et al. (2005) found differences between older and young participants in terms of conflict style; their results indicated that older participants prefer accommodating conflict style. In the same vein, Çetin and Hacifazlioğlu (2011) pointed out significant differences between means of estimates of CM styles used by a university academics in favor of title, experience, gender as well as university type. It is therefore useful to identify the role of personal characteristics of study participants in adopting a particular style of conflict management.

\section{References Références Referencias}

1. Abbas, S. and Karage, A. (2015). Workplace conflict management styles: Comparative study of Indian and Nigerian employees. European Journal of Business and Management, 7(23), 44-54.
2. Alper, S., Tjosvold, D. and Law, K. (2000). Conflict management, efficacy, and performance in organizational teams. Personnel psychology, 53(3), 625-642.

3. Aritzeta, A., Ayestaran, S. and Swailes, S. (2005). Team role preference and conflict management styles. International Journal of conflict management, 16(2), 157-182.

4. Baillien, E., Bollen, K., Euwema, M. and De Witte, H. (2014). Conflicts and conflict management styles as precursors of workplace bullying: A two-wave longitudinal study. European Journal of Work and Organizational Psychology, 23(4), 511-524.

5. Barbuto Jr, J. and Xu, Y. (2006). Sources of motivation, interpersonal conflict management styles, and leadership effectiveness: A structural model. Psychological reports, 98(1), 3-20.

6. Bell, S. (2007). Deep-level composition variables as predictors of team performance: a metaanalysis. Journal of applied psychology, 92(3), 595.

7. Caputo, A., Ayoko, O. and Amoo, N. (2018). The moderating role of cultural intelligence in the relationship between cultural orientations and conflict management styles. Journal of Business Research, 89, 10-20.

8. Carley, K. and Prietula, M. (2014). The virtual design team: Simulating how organization structure and information processing tools affect team performance. Journal of Organization design, 1(2), 14-41.

9. Çetin, M. and Hacifazlioğlu, Ö. (2011). Academics' conflict management styles. Doğuş Üniversitesi Dergisi, 5(2), 155-162.

10. Chan, K., Huang, X. and Ng, P. (2008). Managers' conflict management styles and employee attitudinal outcomes: The mediating role of trust. Asia Pacific Journal of Management, 25(2), 277-295.

11. D'Innocenzo, L., Mathieu, J. and Kukenberger, M. (2016). A meta-analysis of different forms of shared leadership-team performance relations. Journal of Management, 42(7), 1964-1991.

12. DeChurch, L. and Marks, M. (2001). Maximizing the benefits of task conflict: The role of conflict management. International Journal of Conflict Management, 12(1), 4-22.

13. Dionne, S. D., Yammarino, F. J., Atwater, L. E., \& Spangler, W. D. (2004). Transformational leadership and team performance. Journal of organizational change management, 17(2), 177-193.

14. Dionne, S., Yammarino, F., Atwater, L. and Spangler, W. (2004). Transformational leadership and team performance. Journal of organizational change management, 17(2), 177-193.

15. Gardner, A., Scott, D. and AbdelFattah, K. (2017). Do great teams think alike? An examination of team 
mental models and their impact on team performance. Surgery, 161(5), 1203-1208.

16. Guimera, R., Uzzi, B., Spiro, J. and Amaral, L. (2005). Team assembly mechanisms determine collaboration network structure and team performance. Science, 308(5722), 697-702.

17. Gull, S., Habib-ur-Rehman and Zaidi, S. (2012). Impact of conflict management styles on team effectiveness in textile sector of Pakistan. International Journal of Business and Management, 7(3), 219-229.

18. Hair Jr., J. Celsi, M., Money, A., Samouel, P. and Page, M. (2015). The Essentials of Business Research Methods. New York: Taylor \& Francis: Routledge.

19. Hair, J., Ringle, C. and Sarstedt, M. (2011). PLSSEM: Indeed a silver bullet. Journal of Marketing theory and Practice, 19(2), 139-152.

20. Hempel, P., Zhang, Z. and Tjosvold, D. (2009). Conflict management between and within teams for trusting relationships and performance in China. Journal of Organizational Behavior: The International Journal of Industrial, Occupational and Organizational Psychology and Behavior, 30(1), 41-65.

21. Howard, L. W., Turban, D. and Hurley, S. (2016). Cooperating teams and competing reward strategies: Incentives for team performance and firm productivity. Journal of Behavioral and Applied Management, 3(3), 1054.

22. Keller, R. (2006). Transformational leadership, initiating structure, and substitutes for leadership: A longitudinal study of research and development project team performance. Journal of applied psychology, 91(1), 202.

23. Kim, E., Yamaguchi, A., Kim, M. and Miyahara, A. (2015). Effects of taking conflict personally on conflict management styles across cultures. Personality and Individual Differences, 72, 143-149.

24. Kim, T., Wang, C., Kondo, M. and Kim, T. (2007). Conflict management styles: the differences among the Chinese, Japanese, and Koreans. International journal of conflict management, 18(1), 23-41.

25. Kirkman, B. L., Rosen, B., Tesluk, P. and Gibson, C. (2004). The impact of team empowerment on virtual team performance: The moderating role of face-toface interaction. Academy of Management Journal, 47(2), 175-192.

26. Kirkman, B., Rosen, B., Tesluk, P. and Gibson, C. (2004). The impact of team empowerment on virtual team performance: The moderating role of face-toface interaction. Academy of Management Journal, 47(2), 175-192.

27. Kostopoulos, K. and Bozionelos, N. (2011). Team exploratory and exploitative learning: Psychological safety, task conflict, and team performance. Group \& Organization Management, 36(3), 385-415.
28. Kuhn, T. and Poole, M. (2000). Do conflict management styles affect group decision making? Evidence from a longitudinal field study. Human communication research, 26(4), 558-590.

29. Liu, X., Magjuka, R. and Lee, S. (2008). An examination of the relationship among structure, trust, and conflict management styles in virtual teams. Performance improvement quarterly, 21(1), 77-93.

30. Lyubovnikova, J., Legood, A., Turner, N. and Mamakouka, A. (2017). How authentic leadership influences team performance: The mediating role of team reflexivity. Journal of business Ethics, 141(1), 59-70.

31. Ma, Z., Erkus, A. and Tabak, A. (2010). Explore the impact of collectivism on conflict management styles: a Turkish study. International Journal of Conflict Management, 21(2), 169-185.

32. McAuliffe, E., De Brún, A., Ward, M., O'Shea, M., Cunningham, U., O'Donovan, R., McGinley, S., Fitzsimons, J., Corrigan, S. and McDonald, N. (2017). Collective leadership and safety cultures (Co-Lead): protocol for a mixed-methods pilot evaluation of the impact of a co-designed collective leadership intervention on team performance and safety culture in a hospital group in Ireland. BMJ open, 7(11), 1-7.

33. Melita P., Douglas, C., Ferris, G., Ammeter, A. and Buckley, M. (2003). Emotional intelligence, leadership effectiveness, and team outcomes. The International Journal of Organizational Analysis, 11(1), 21-40.

34. Ogedegbe, G., Mancuso, C., Allegrante, J. and Charlson, M. (2003). Development and evaluation of a medication adherence self-efficacy scale in hypertensive African-American patients. Journal of clinical epidemiology, 56(6), 520-529.

35. Paul, S., Seetharaman, P., Samarah, I. and Mykytyn, P. (2004). Impact of heterogeneity and collaborative conflict management style on the performance of synchronous global virtual teams. Information \& Management, 41(3), 303-321.

36. Rahim, A. (2000). Empirical studies on managing conflict. International Journal of conflict management; 11(1), 5-8.

37. Rahim, M., Psenicka, C., Polychroniou, P., Zhao, J., Yu, C., Chan, K., Susana, K., Alves, M., Lee, C., Rahman, M., Ferdausy, S. and Wyk, R. (2002). A model of emotional intelligence and conflict management strategies: A study in seven countries. The International journal of organizational analysis, 10(4), 302-326.

38. Riasi, A. and Asadzadeh, N. (2015). The relationship between principals' reward power and their conflict management styles based on Thomas-Kilmann conflict mode instrument. Management Science Letters, 5(6), 611-618. 
39. Rizkalla, L., Wertheim, E. and Hodgson, L. (2008). The roles of emotion management and perspective taking in individuals' conflict management styles and disposition to forgive. Journal of Research in Personality, 42(6), 1594-1601.

40. Saeed, T., Almas, S., Anis-ul-Haq, M. and Niazi, G. (2014). Leadership styles: relationship with conflict management styles. International Journal of Conflict Management, 25(3), 214-225.

41. Shih, H. and Susanto, E. (2010). Conflict management styles, emotional intelligence, and job performance in public organizations. International Journal of Conflict Management, 21(2), 147-168.

42. Shook, C. L., Ketchen Jr, D. J., Hult, G. and Kacmar, K. (2004). An assessment of the use of structural equation modeling in strategic management research. Strategic management journal, 25(4), 397-404.

43. Slabbert, A. (2004). Conflict management styles in traditional organizations. The Social Science Journal, 41(1), 83-92.

44. Somech, A., Desivilya, H. and Lidogoster, H. (2009). Team conflict management and team effectiveness: The effects of task interdependence and team identification. Journal of Organizational Behavior: The International Journal of Industrial, Occupational and Organizational Psychology and Behavior, 30(3), 359-378.

45. Stanley, C. and Algert, N. (2007). An exploratory study of the conflict management styles of department heads in a research university setting. Innovative Higher Education, 32(1), 49-65.

46. Stewart, G. and Barrick, M. (2000). Team structure and performance: Assessing the mediating role of intrateam process and the moderating role of task type. Academy of management Journal, 43(2), 135-148.

47. Thompson, B., Haidet, P., Borges, N., Carchedi, L., Roman, B., Townsend, M., Butler A., Swanson D., Anderson M. and Levine, R. E. (2015). Team cohesiveness, team size and team performance in team-based learning teams. Medical education, 49(4), 379-385.

48. Ting-Toomey, S., Oetzel, J. and Yee-Jung, K. (2001). Self-construal types and conflict management styles. Communication Reports, 14(2), 87-104.

49. Tröster, C., Mehra, A. and Van Knippenberg, D. (2014). Structuring for team success: The interactive effects of network structure and cultural diversity on team potency and performance. Organizational Behavior and Human Decision Processes, 124(2), 245-255.

50. Yi, Y., Ndofor, H., He, X. and Wei, Z. (2018). Top management team tenure diversity and performance: The moderating role of behavioral integration. IEEE Transactions on Engineering Management, 65(1), 21-33.

51. Yu, C., Sardessai, R., Lu, J. and Zhao, J. (2006). Relationship of emotional intelligence with conflict management styles: an empirical study in China. International Journal of Management and Enterprise Development, 3(1/2), 19.

52. Zaman, U. and Saif, M. (2016). Perceived accountability and conflict management styles as predictors of job performance of public officials in Pakistan. Gomal University Journal of Research [GUJR], 32(2).

53. Zhang, J., Li, H., (Robert) Luo, X. and Warkentin, M. (2017). Exploring the effects of the privacy-handling Management styles of social networking sites on user satisfaction: A conflict management perspective. Decision Sciences, 48(5), 956-989.

54. Zhang, Y., Harwood, J. and Hummert, M. (2005). Perceptions of conflict management styles in Chinese intergenerational dyads. Communication Monographs, 72(1), 71-91.

55. Zhou, W., Vredenburgh, D. and Rogoff, E. (2015). Informational diversity and entrepreneurial team performance: moderating effect of shared leadership. International Entrepreneurship and Management Journal, 11(1), 39-55. 